\title{
An investigation into the degradation of polyaniline films grown on iron from oxalic acid
}

\author{
Anna M. Fenelon, Carmel B. Breslin* \\ Department of Chemistry, National University of Ireland Maynooth, Maynooth, Co. Kildare, Ireland \\ Received 5 September 2003; received in revised form 6 February 2004; accepted 12 February 2004
}

Available online 22 April 2004

\begin{abstract}
The electrosynthesis of polyaniline at iron from an oxalic acid solution and at platinum from a sulphuric acid solution was compared with a view to determining the extent of film degradation during formation of polyaniline at iron. It was found that polyaniline grown from oxalic acid is less susceptible to degradation, due to the shielding effect of the oxalate counter anions. The benzoquinone/hydroquinone redox couple was detected for polyaniline films formed on platinum and cycled to $1.3 \mathrm{~V} / \mathrm{SCE}$, however, this redox species was not detected during the electropolymerization of aniline at iron polarized to potentials of $1.5 \mathrm{~V} / \mathrm{SCE}$.
\end{abstract}

(c) 2004 Elsevier B.V. All rights reserved.

Keywords: Polyaniline; Degradation; Iron; Oxalate; Sulphate

\section{Introduction}

In recent years there has been much interest in conducting polymers and in particular polyaniline. This interest stems from the fact that polyaniline finds applications in the fields of battery technology [1,2] in electrochromic devices [3] and in corrosion protection [4-12].

The electrodeposition of polyaniline on inert metals, such as platinum and gold, occurs readily and the properties of the polymer can be controlled on varying the electrosynthesis conditions. However, deposition of polyaniline at iron electrodes is more difficult due to the high rate of iron dissolution in acidic media. This has been overcome by the deposition of a passive layer at the iron electrode either prior to, or during, the polymer deposition process [4-7]. However, in order to initiate electropolymerization at corrosion susceptible substrates, such as iron, relatively high anodic potentials must be applied. For example, Martyak et al. [8] formed polyaniline at steel from an oxalic acid solution by potential cycling up to 1.6 V/AgCl. Rajagopolan and Iroh [9] used potentials higher than 1.2 V/SCE in depositing copolymers of polyaniline and polypyrrole from an oxalic acid solution. In addition, Lacaze and coworkers [5] and Camalet et al. [10] used potentials in the region of 1.2 V/SCE, while

\footnotetext{
* Corresponding author. Tel.: +353-1-708-3770; fax: +353-1-708-3815. E-mail address: cb.breslin@may.ie (C.B. Breslin).
}

Malik et al. [11] used potentials up to 0.9 V/SCE and Sazou and Georgolios [4] employed potentials close to 1.5 V/SCE in the electrosynthesis of polyaniline at iron from oxalate media.

However, it is well know that the application of high anodic potentials, above $0.7 \mathrm{~V} / \mathrm{SCE}$ in the electrochemical synthesis of polyaniline at inert substrates gives rise to degradation of the polymer [12-16]. For example, Kobayashi et al. [12] have observed the degradation of polyaniline films at potentials greater than $0.7 \mathrm{~V} / \mathrm{SCE}$ and have attributed a pair of redox waves close to $0.5 \mathrm{~V} / \mathrm{SCE}$ in the voltammetric response of the polymer to a benzoquinone/hydroquinone couple. Stilwell and Park [13] performed spectrophotometric experiments on oxidized polyaniline and identified benzoquinone as the major soluble degradation product, formed as a consequence of hydrolysis reactions. Cui et al. [14] report the presence of hydrolysis products in polyaniline films, which inhibit the fibrilious growth of polyaniline and gives rise to a powdery film morphology. Duić et al. [15] suggest that in acidic conditions two pairs of middle peaks are observed in the cyclic voltammograms which originate from the hydrolysis of aminodiphenylamine, a dimer intermediate of polymer growth.

In this study, the characteristics of polyaniline films formed on iron from oxalic acid using these high anodic potentials are compared to polyaniline films formed on pure platinum under conditions favouring the formation of pure and degraded films. 


\section{Experimental}

Electrodes were prepared from pure iron (99.995\%) and platinum electrodes (99.999\%). The electrodes were provided in rod form $(0.5$ and $0.4 \mathrm{~cm}$ in diameter for iron and platinum, respectively). These rods were embedded in epoxy resin in a Teflon holder with electrical contact being achieved by means of a copper wire threaded into the base of the metal sample. Prior to each test, the exposed surfaces were polished to a smooth surface finish, using $1200 \mathrm{~g} \mathrm{SiC}$ and rinsed with distilled water. High-density graphite rods were used as the auxiliary electrodes and a saturated calomel electrode (SCE) was used as the reference electrode, with all potentials represented relative to this electrode. The electrolytes were prepared using analytical grade reagents and distilled water. The electropolymerization solution consisted of $0.1 \mathrm{~mol} \mathrm{dm}^{-3}$ aniline added to $0.1 \mathrm{~mol} \mathrm{dm}^{-3}$ oxalic acid in the case of iron electrodes, and to $1.0 \mathrm{~mol} \mathrm{dm}^{-3}$ sulphuric acid in the case of the platinum electrodes. The aniline was distilled prior to use and stored under nitrogen in the dark.

Electrochemical measurements were carried out using an EG\&G Potentiostat, Model 263 or a Solartron EI 1287 electrochemical interface. The polymers were formed using potential cycling at a scan rate of $10 \mathrm{mV} / \mathrm{s}$.

Molecular masses of the polymers were estimated using gel permeation chromatography (GPC). A Hewlett Packard 1050 series instrument was fitted with a PLgel $5 \mu \mathrm{m}$ I.D. Minimix-C, $25 \mathrm{~cm}$ length column. The mobile phase was $N$-methyl-2-pyrrolidinone (NMP), HPLC grade supplied by Aldrich, at a flow rate of $0.2 \mathrm{ml} / \mathrm{min}$. The column temperature was $50^{\circ} \mathrm{C}$ and the detector was a refractive index detector operating at a temperature of $50^{\circ} \mathrm{C}$. Polyaniline samples were dissolved in NMP using a sonicator, filtered and then injected into the column. Polystyrene samples, with molecular masses between 780 and 114,200 amu, were used as standards.

UV-Vis spectroscopy was carried out using a Varian Cary 50 UV-Vis spectrometer. All samples were dissolved in $N$-methyl-pyrrolidinone. This solution was then transferred to a quartz UV-cell of $1 \mathrm{~cm}$ in path length. Measurements were then made from 800 to $300 \mathrm{~nm}$.

\section{Results and discussion}

\subsection{Influence of cycling conditions on the formation of polyaniline}

In Fig. 1 typical voltammograms recorded during the electropolymerization of aniline at iron and platinum are shown. The data presented in Fig. 1(a) show the first and tenth cycles recorded between -0.6 and $1.5 \mathrm{~V} / \mathrm{SCE}$ at $10 \mathrm{mV} / \mathrm{s}$ in $0.1 \mathrm{~mol} \mathrm{dm}^{-3}$ aniline and $0.1 \mathrm{~mol} \mathrm{dm}^{-3}$ oxalic acid. This method of electropolymerization has been used previously by Sazou and Georgolios [4] and gives rise to the formation of adherent and reproducible polyaniline layers. As re-
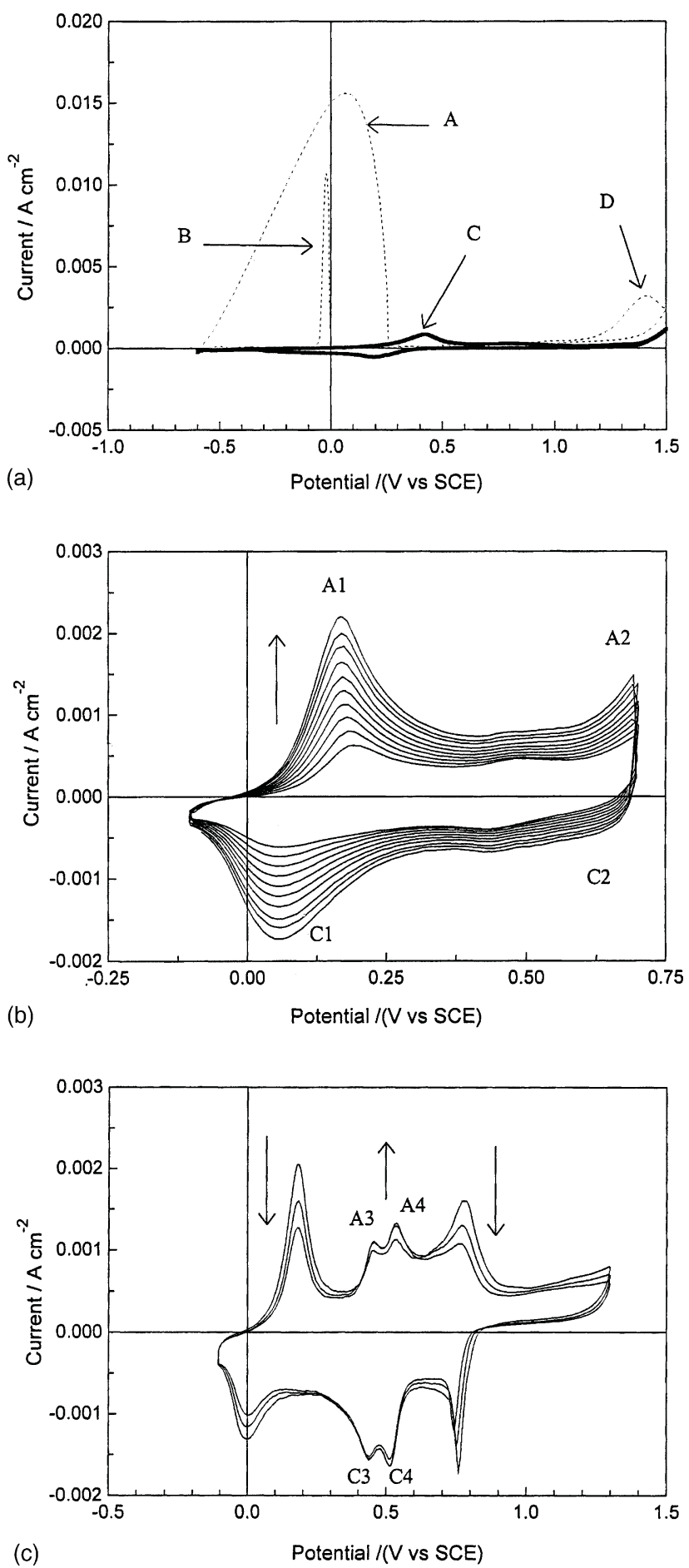

Fig. 1. (a) Cyclic voltammograms recorded for iron polarized in $0.1 \mathrm{~mol} \mathrm{dm}^{-3}$ oxalic acid containing $0.1 \mathrm{~mol} \mathrm{dm}^{-3}$ aniline. Cycles 1 (-- -) and 10 (a). (b) Cyclic voltammograms recorded for a platinum electrode in $1.0 \mathrm{~mol} \mathrm{dm}^{-3} \mathrm{H}_{2} \mathrm{SO}_{4}$ containing $0.1 \mathrm{~mol} \mathrm{dm}^{-3}$ aniline, between -0.1 and $0.78 \mathrm{~V} / \mathrm{SCE}$ at $10 \mathrm{mV} / \mathrm{s}$. (c) Cyclic voltammograms recorded for polyaniline-coated platinum in $1.0 \mathrm{~mol} \mathrm{dm}^{-3} \mathrm{H}_{2} \mathrm{SO}_{4}$ between $-0.1 \mathrm{~V}$ and $1.3 \mathrm{~V} / \mathrm{SCE}$; cycles 2-4. 
ported earlier [4,5], there is a clear difference between the first cycle and the remaining cycles. Highlighted in Fig. 1(a) are four oxidation peaks. Peak A, which is observed during the forward scan of the first cycle, corresponds to dissolution of iron in the acidic solution at low potentials. However, this peak disappears after the first cycle. At potentials above $0.1 \mathrm{~V} / \mathrm{SCE}$, passivation of the iron electrode occurs, by deposition of an insoluble Fe(II) oxalate layer on the surface. At potentials above 1.35 V/SCE oxidation of the aniline monomer occurs, corresponding to Peak D. On the back sweep, near $0 \mathrm{~V} / \mathrm{SCE}$, a sharp reactivation peak (Peak B) is observed and this corresponds to reactivation of iron and is gradually reduced as the cycle number increases. Peak C, which corresponds to a redox couple is consistent with the electrochemical response of the polyaniline deposit and is clearly evident in the tenth cycle. On repetitive cycling of the potential, a progressive increase in the height of this peak is seen, while the reactivation and dissolution peaks (B and A) are no longer evident. This is indicative of the build-up of surface bound electroactive material $[14,17]$. This process of polyaniline deposition at the corrosion susceptible iron surface from oxalic acid has been discussed by many authors $[4,5,18]$, but generally the mechanism proposed by Mengoli and Musiani [18] is adopted, where the electrode becomes passivated by an oxalate/oxide layer on polarization in the oxalate solution.

However, as shown from a comparison of Fig. 1(b) and (c), the application of these high anodic potentials to polyaniline formed on pure platinum leads to the formation of degradation products. It should be noted here that polyaniline could not be deposited from oxalic acid on platinum and so the polyaniline layer was grown on the inert substrate from $1.0 \mathrm{~mol} \mathrm{dm}^{-3} \mathrm{H}_{2} \mathrm{SO}_{4}$. In Fig. 1(b), where the potential was cycled up to a relatively low potential of $0.76 \mathrm{~V} / \mathrm{SCE}$ the polyaniline is relatively free from degradation products. The redox couple labelled as A1/C1 corresponds to the conversion of the non-conducting leucoemeraldine form to the conducting emeraldine salt form. This transition is accompanied by a colour change from colourless to green. Couple A2/C2, which is only slightly evident because of the low switching potential, corresponds to the transition from the emeraldine salt/base to the oxidized pernigraniline, and is accompanied by a colour change of green to violet.

However, as shown in Fig. 1(c), where the pure polyaniline film formed in Fig. 1(b) was cycled in the monomer-free acid solution up to a high vertex potential of $1.3 \mathrm{~V} / \mathrm{SCE}$, additional redox couples can be seen near to 0.45 and $0.54 \mathrm{~V} / \mathrm{SCE}$. These are labelled as A3/C3 and A4/C4. These data are similar to those reported by Duić et al. [15] who suggest that under acidic conditions two pairs of 'middle peaks' are observed. The peaks at the higher potential of $0.54 \mathrm{~V} / \mathrm{SCE}$ have also been associated with the formation of soluble benzoquinone, a degradation product of polyaniline [12-16]. The extent of film degradation with continued cycling up to $1.3 \mathrm{~V} / \mathrm{SCE}$ increases; the peak currents associated with the 'middle peaks' at 0.45 and $0.54 \mathrm{~V} / \mathrm{SCE}$
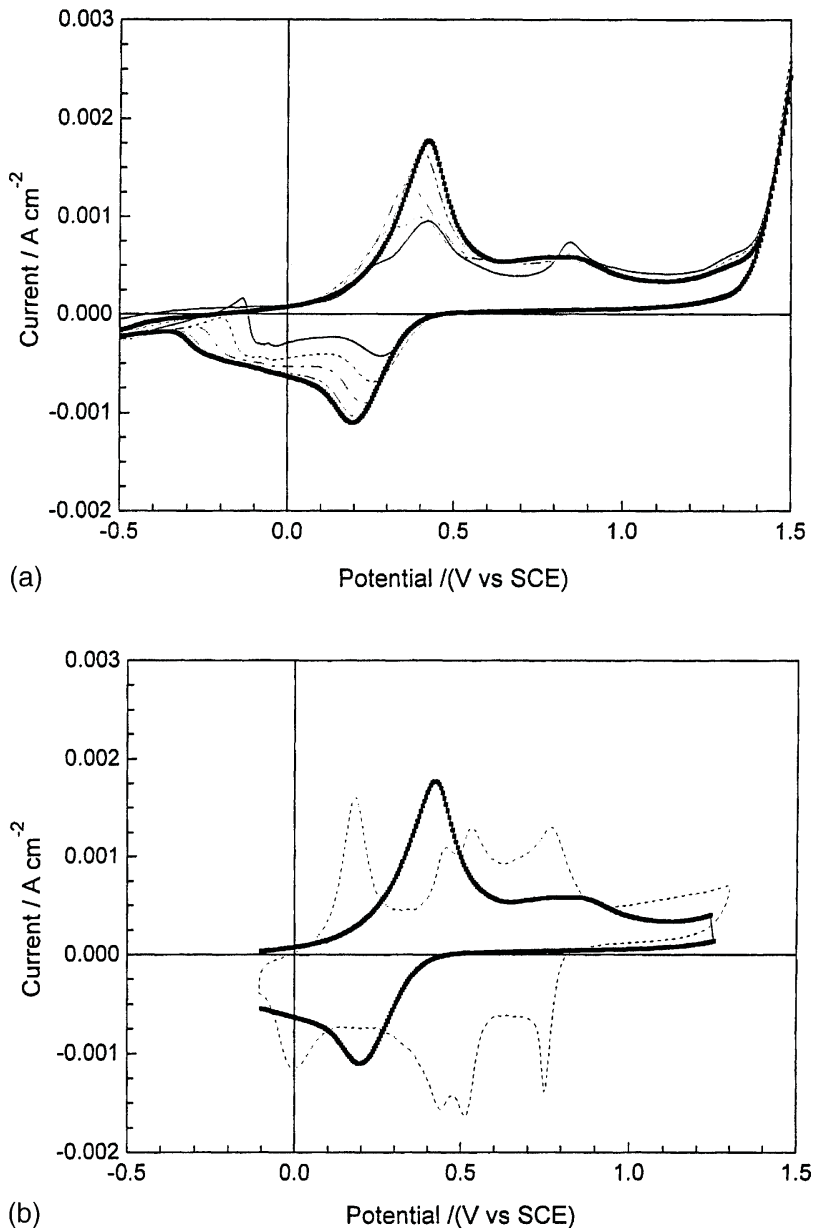

Fig. 2. (a) Cyclic voltammograms recorded for iron polarized in $0.1 \mathrm{~mol} \mathrm{dm}^{-3}$ oxalic acid containing $0.1 \mathrm{~mol} \mathrm{dm}^{-3}$ aniline. Cycles $3(-)$, $5(-), 7(-\cdot-), 9(-\cdot-)$ and 10 (.....). (b) Cyclic voltammograms recorded for $(-)$ iron polarized in $0.1 \mathrm{~mol} \mathrm{dm}^{-3}$ oxalic acid containing $0.1 \mathrm{~mol} \mathrm{dm}^{-3}$ aniline (cycle 4$)$ and $(\cdots)$ polyaniline-coated platinum in $1.0 \mathrm{~mol} \mathrm{dm}^{-3} \mathrm{H}_{2} \mathrm{SO}_{4}$ (cycle 4).

increase, while the peak currents corresponding to the leucoemeraldine to emeraldine transition and the emeraldine to pernigraniline transition decrease, as depicted in the plot.

This domination of the polyaniline by-products at these high potentials is not seen, at least to the same extent, in the case of iron, Fig. 1(a). There is no evidence of the A3/C3 couple. This can be seen more clearly in Fig. 2(a), where the early cycles, which are dominated by the dissolution of iron, are removed. In this figure cycles 3, 5, 7, 9 and 10 are shown. Although there is indeed considerable difference between the voltammetric responses shown in Figs. 1(b) and 2(a), these appear to be related more to the variation in the nature of the substrate and the $\mathrm{pH}$ of the electropolymerization media. The iron system consists of an iron-oxalate/oxide-polyaniline combination, which has a much higher resistivity than the platinum/polyaniline system. Indeed, the high frequency impedance measured for the iron system was $60 \Omega \mathrm{cm}^{2}$ compared to values close to $1.0 \Omega \mathrm{cm}^{2}$ for the platinum-polyaniline system. Also, the $\mathrm{pH}$ 
of $0.1 \mathrm{~mol} \mathrm{dm}^{-3}$ oxalic acid is 1.6 compared to a $\mathrm{pH}$ of 0.6 for $1.0 \mathrm{~mol} \mathrm{dm}^{-3} \mathrm{H}_{2} \mathrm{SO}_{4}$. Both redox peaks are clearly separated in the case of the platinum substrate, Fig. 1(b). However, on iron, although both oxidation peaks are visible in the third cycle only one polyaniline peak dominates the response after ten cycles. However, with continued film growth, this peak continues to grow and at no point is there any evidence of the middle peaks observed in Fig. 1(c). Although it may be argued that the broad polyaniline peak masks the presence of the degradation products, it is clear from the comparison in Fig. 2(b) that this is not the case. In this figure, the voltammograms recorded during the electropolymerization at iron are compared with the voltammograms recorded for the polyaniline-coated platinum electrode polarized in $\mathrm{H}_{2} \mathrm{SO}_{4}$. Although there is some overlap in the peaks during the oxidation waves, the reduction waves corresponding to the degradation products occur at very different potentials and it is very clear that these are not present for the iron system.

\subsection{Detection of benzoquinone}

Benzoquinone, the major degradation product of polyaniline, is soluble, readily undergoes a redox reaction, Eq. (1), and has a characteristic redox couple near 0.50 V/SCE [12]:<smiles>O=C1C=CC(=O)C=C1</smiles>
$2 \mathrm{e}, 2 \mathrm{H}^{+}$

Oxidized quinoid unit

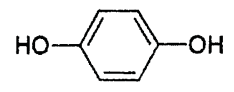

Reduced benzenoid unit

A series of experiments was designed in an attempt to isolate and detect this degradation product. However, it was first necessary to assess the electroactivity of the benzoquinone-hydroquinone couple at a polyaniline modified iron electrode. In this experiment polyaniline was grown at iron by potential cycling at $10 \mathrm{mV} / \mathrm{s}$, between -0.6 and $1.5 \mathrm{~V} / \mathrm{SCE}$ in $0.1 \mathrm{~mol} \mathrm{dm}^{-3}$ oxalic acid containing $0.1 \mathrm{~mol} \mathrm{dm}^{-3}$ aniline. Following eight cycles, hydroquinone was added to the polymerization solution to give a final concentration of $10 \mathrm{mmol} \mathrm{dm}^{-3}$. The presence of the benzoquinone-hydroquinone redox couple was evident at $E_{1 / 2}=0.32 \mathrm{~V} / \mathrm{SCE}$. The forward peak current, associated with hydroquinone oxidation at $0.42 \mathrm{~V} / \mathrm{SCE}$ was $1.2 \times 10^{-3} \mathrm{~A} \mathrm{~cm}^{-2}$ compared to the current of $4.05 \times 10^{-4} \mathrm{~A} \mathrm{~cm}^{-2}$ recorded at $0.42 \mathrm{~V} / \mathrm{SCE}$ prior to the addition of hydroquinone. A similar experiment was performed at polyaniline modified platinum electrode. In this case a pure polyaniline film was grown at a platinum electrode by potential cycling between -0.1 and $0.75 \mathrm{~V} / \mathrm{SCE}$ at $50 \mathrm{mV} / \mathrm{s}$ in $1.0 \mathrm{~mol} \mathrm{dm}^{-3} \mathrm{H}_{2} \mathrm{SO}_{4}$ containing $0.1 \mathrm{~mol} \mathrm{dm}^{-3}$ aniline. After 20 cycles hydroquinone was added to the electropolymerization solution. An oxidation peak with a 10 -fold increase in current was observed at 0.5 V/SCE. From these results it is clear that the benzoquinone-hydroquinone redox couple is electroactive at a polyaniline modified iron electrode. However, the oxidation peak potential of hy-

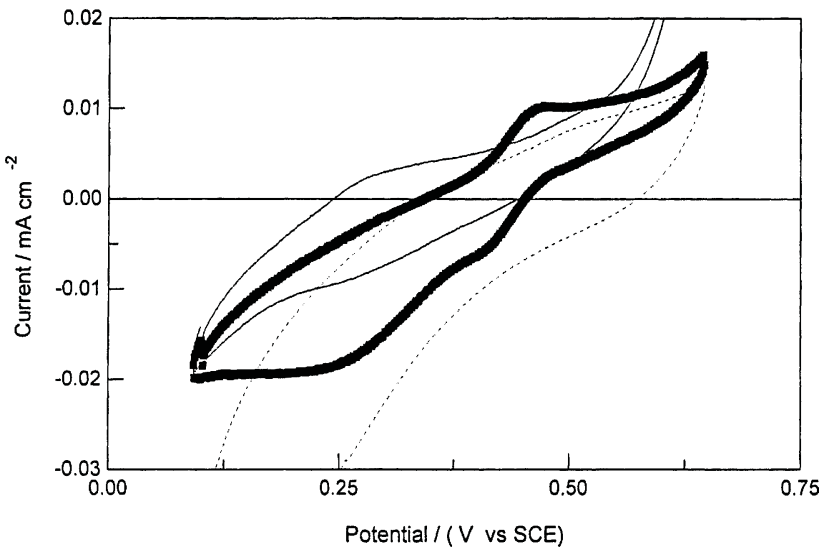

Fig. 3. Cyclic voltammograms recorded for platinum cycled in the solutions used $(-)$ to prepare pure polyaniline at platinum, $(-)$ polyaniline prepared at platinum using potentials cycled to $1.3 \mathrm{~V} / \mathrm{SCE}$ and $(\cdots)$ polyaniline prepared at iron.

droquinone is close to the potential adopted by the first redox transition of polyaniline. The oxidation of hydroquinone occurs at $0.42 \mathrm{~V} / \mathrm{SCE}$ and that of polyaniline at $0.36 \mathrm{~V} / \mathrm{SCE}$ at an oxalate modified iron electrode. To ensure that the degradation of polyaniline was not masked by the first redox transition of polyaniline an additional experiment was set up to detect the soluble benzoquinone in solution. In these experiments both degraded and pure polyaniline were grown on a platinum substrate in $5.0 \mathrm{ml}$ of $1.0 \mathrm{~mol} \mathrm{dm}^{-3} \mathrm{H}_{2} \mathrm{SO}_{4}$ containing a $0.1 \mathrm{~mol} \mathrm{dm}^{-3}$ aniline solution. The degraded polyaniline was formed by potential cycling at $10 \mathrm{mV} / \mathrm{s}$ to a high potential of $1.3 \mathrm{~V} / \mathrm{SCE}$, until the oxidation peaks associated with polyaniline degradation near $0.5 \mathrm{~V} / \mathrm{SCE}$ dominated the electrochemical response; in this case 15 cycles. A pure polyaniline film was prepared by potential cycling initially to $1.0 \mathrm{~V} / \mathrm{SCE}$ followed by 50 cycles to $0.75 \mathrm{~V} / \mathrm{SCE}$ at $50 \mathrm{mV} / \mathrm{s}$. A freshly polished platinum electrode was then placed into the solution following polymer growth and cycled between 0.1 and $0.65 \mathrm{~V} / \mathrm{SCE}$. A similar experiment was then recorded for polyaniline grown on iron; in $0.1 \mathrm{~mol} \mathrm{dm}^{-3}$ oxalic acid and $0.1 \mathrm{~mol} \mathrm{dm}^{-3}$ aniline by cycling between -0.6 and 1.5 V/SCE for 10 cycles. These results are presented in Fig. 3. Evident in this figure is the presence of the benzoquinone/hydroquinone redox couple at the platinum electrode cycled in the solution where the degraded polyaniline film was formed. As expected, this couple is absent in the case of the solution in which a pure polyaniline layer was deposited. However, the most interesting feature to note is the absence of the benzoquinone redox couple at the platinum electrode cycled in the solution in which polyaniline was grown at iron from oxalic acid, despite the very high potentials used. Although these measurements may not be sensitive to very low concentrations of benzoquinone, they clearly show that there is a considerable difference between the extent of build-up of the degradation products during the electropolymerization reactions at iron and platinum when cycled to high anodic potentials. 


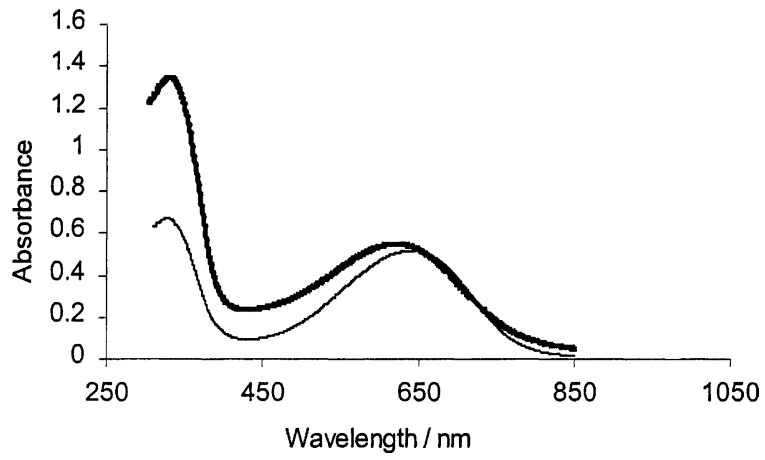

Fig. 4. UV-Vis spectra recorded in NMP for polyaniline prepared at (-) iron and at $(-)$ platinum using low potential.

\subsection{Characterization of the polymer}

The polyaniline layers grown on iron were further characterized using UV-Vis spectroscopy and gel permeation chromatography. For comparative purposes, similar measurements were performed on a polyaniline film formed from $\mathrm{H}_{2} \mathrm{SO}_{4}$ on pure platinum. These films were deposited using cyclic voltammetry, scanning the potential between the limits of -200 and $780 \mathrm{mV} / \mathrm{SCE}$. This procedure, using relatively low anodic potentials, ensured that the polyaniline deposit was pure and free of degradation, or decomposition, products. These results are presented in Figs. 4 and 5, respectively. In both cases, the polymer layers were dissolved in NMP.

The UV-Vis spectra, Fig. 4, exhibit two absorption bands, one centred at $325 \mathrm{~nm}$ and the other, in the case of polyaniline grown on platinum at $642 \mathrm{~nm}$, and for the polymer grown on iron at $620 \mathrm{~nm}$. The most interesting aspect of these results is that both traces are very similar indicating that the polymer layers formed on the active and inert metal are similar. There is some differences in the magnitude of the ab-

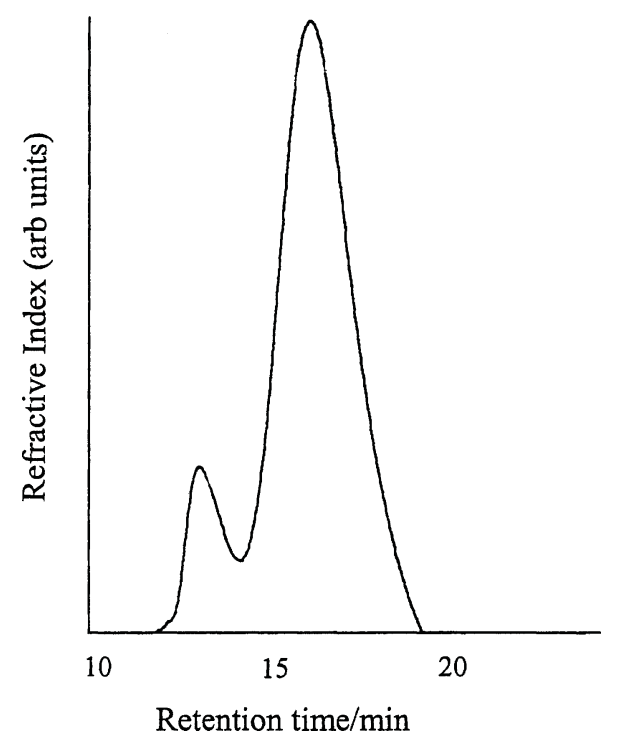

Fig. 5. Gel permeation chromatogram recorded for polyaniline. sorbance, but this is related to variations in the concentration of the polymer dissolved in NMP. Although there is some ambiguity in the assignment of these bands, particularly the band at $626 \mathrm{~nm}$, most researchers accept that the transition at $320 \mathrm{~nm}$ corresponds to a $\pi-\pi^{*}$ transition, while the intensity of the band at $620 \mathrm{~nm}$ depends on the oxidation state of the polymer.

A typical chromatogram is shown in Fig. 5. The characteristic bimodal molecular weight distribution, which has been reported previously for polyaniline, in the form of the emeraldine base $[19,20]$ is evident. The presence of the first peak, i.e. the high molecular weight fraction, has been attributed to aggregates of polymer chains linked through hydrogen bonding. This aggregation is the result of interchain hydrogen bonding between the amine and imine nitrogen atoms in the polyaniline backbone $[19,20]$. These data are similar to those reported by MacDiarmid and coworkers [19] for chemically synthesized polyaniline in the emeraldine base state. Furthermore, near identical data were recorded for the polymer samples formed on platinum and iron. The number average molecular masses recorded for the polyaniline deposited at iron and platinum were $60.7 \times 10^{3}$ and $62.8 \times 10^{3} \mathrm{amu}$, respectively. The area of the high molecular weight fraction accounted for $11.4 \%$ of the total area for the platinum and $12.3 \%$ for the iron sample. This shows that there is very little variation between both systems; with similar hydrogen bonding and polymer chain lengths being recorded in both systems.

Although these measurements do not enable the detection of soluble degradation products, they do show that the final polymers are very similar in terms of molar mass and electronic transitions and point to the fact that the polyaniline coatings formed on iron are relatively free from any significant modification due to the presence of degradation products.

\subsection{Role of oxalic acid}

It appears that the oxalic acid has a stabilizing effect on the polymer formed on iron. This can be seen by comparing the stability of a polyaniline film grown on platinum in oxalic and sulphuric acids. In these experiments, pure polyaniline films were grown on platinum electrodes from sulphuric acid. Following growth, the polymer-coated electrode was then cycled in $1.0 \mathrm{~mol} \mathrm{dm}^{-3} \mathrm{H}_{2} \mathrm{SO}_{4}, 0.1 \mathrm{~mol} \mathrm{dm}^{-3} \mathrm{H}_{2} \mathrm{SO}_{4}$ or cycled in $0.1 \mathrm{~mol} \mathrm{dm}^{-3}$ oxalic acid up to a vertex potential of $1.3 \mathrm{~V} / \mathrm{SCE}$ in the absence of the monomer.

The peak currents of the first oxidation peak (A1) were plotted as a function of cycle number. These results are presented in Fig. 6. Significant differences are evident for the polymers cycled in the sulphuric and oxalic acids. In the case of the $1.0 \mathrm{~mol} \mathrm{dm}^{-3}$ sulphuric acid solutions, a significant decrease in the magnitude of the peak is seen on increasing cycle number. This is consistent with a loss in electrochemical activity of the polyaniline due to degradation of the polymer film. A somewhat slower rate of degradation is seen 


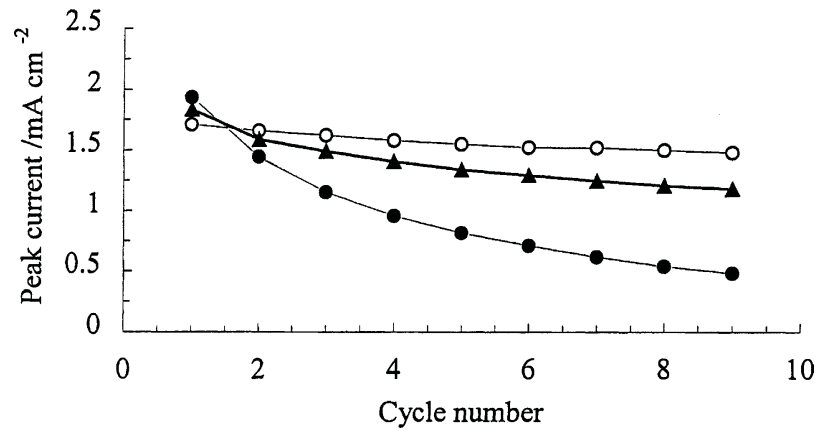

Fig. 6. (a) Peak currents for the oxidation of polyaniline formed at platinum from the leucoemeraldine to emeraldine state cycled in ( $1.0 \mathrm{~mol} \mathrm{dm}^{-3}$ sulphuric acid, (A) $0.1 \mathrm{~mol} \mathrm{dm}^{-3}$ sulphuric acid and ( $\bigcirc$ ) $0.1 \mathrm{~mol} \mathrm{dm}^{-3}$ oxalic acid.

with the lower concentration of $\mathrm{H}_{2} \mathrm{SO}_{4}$, showing clearly that the concentration influences the extent of film degradation. However, the peak currents remain relatively constant, as a function of cycle number, for the oxalate system, indicating a relatively stable polymer. It appears that the oxalate dopant has a stabilizing effect on the polymer films, minimizing breakdown of polyaniline when cycled to high potentials.

It is proposed that these effects are due to the difference in the concentration and nature of the counter ions, namely sulphate and oxalate, and their interactions with the polymer. Lippe and Holze [21] have investigated the anion specific effects in sulphuric and perchloric acids on the over-oxidation of polyaniline and have attributed the higher stability of the polymer in the perchloric acid to a shielding effect. In this analysis they assumed that primarily $\mathrm{SO}_{4}{ }^{2-}$ rather than $\mathrm{HSO}_{4}{ }^{-}$interacts with the polymer when exposed to sulphuric acid. They suggested that perchlorate ions shield the bipolarons better than the sulphate ions from nucleophilic attack by $\mathrm{OH}^{-}$ions, which leads to polyaniline degradation. This explanation is consistent with earlier investigations by Lapkowski and Genies [22] who reported that sulphate anions tend to interact more strongly than perchlorate anions with the positive charges on the polymer chain.

There is much evidence in the literature to suggest that the oxalate interacts with solid surfaces to form a solid bidentate surface structure [23,24]. However, these data are generally obtained with metal oxide surfaces. The oxalate may indeed interact with the polyaniline film to produce a similar bidentate system, but it may also produce a mono-dentate structure (binds with the surface through one carboxylate group). If the latter structure is formed, then it is clear from the schematic shown in Fig. 7 that the mono-charged oxalate anion will shield the bipolaron more efficiently than the di-charged sulphate anion. In this analysis, the bulky arrangement of two mono-deprotonated oxalic acid species would account for the shielding of the bipolaron polyaniline chain from nucleophilic attack. Using Eqs. (2) and (3), and the fact that a $0.1 \mathrm{~mol} \mathrm{dm}^{-3}$ oxalic acid solution was used in these experiments, it is clear that the mono-deprotonated oxalate anion $\left(\mathrm{HOx}^{-}\right)$is in excess of the di-deprotonated form $\left(\mathrm{Ox}^{2-}\right)$. Indeed, the concentration of $\mathrm{HOx}^{-}$is approximately $0.075 \mathrm{~mol} \mathrm{dm}^{-3}$ and $\mathrm{Ox}^{2-}$ is approximately $0.0022 \mathrm{~mol} \mathrm{dm}^{-3}$ :

$$
\begin{array}{ll}
\mathrm{H}_{2} \mathrm{Ox}+\mathrm{H}_{2} \mathrm{O} \rightleftharpoons \mathrm{HOx}^{-}+\mathrm{H}_{3} \mathrm{O}^{+} & \left(K_{\mathrm{a}}=5.6 \times 10^{-2}\right) \\
\mathrm{HOx}^{-}+\mathrm{H}_{2} \mathrm{O} \rightleftharpoons \mathrm{Ox}^{2-}+\mathrm{H}_{3} \mathrm{O}^{+} & \left(K_{\mathrm{a}}=6.5 \times 10^{-5}\right)
\end{array}
$$

However, this alone is not sufficient evidence to rule out the possibility that the $\mathrm{Ox}^{2-}$ species forms a bidentate structure with the polyaniline. Other factors that may be important are the size of the ions and degree of hydration [25]. But, in any case, the polymer is more stable when formed in the oxalate solution despite the high potentials used in the electropolymerization process.

\subsection{Role of the substrate}

The nature of the substrate is also likely to have an influence on the stability of the polymer, under open-circuit conditions. It is well known that a galvanic interaction exists between the iron substrate and the polyaniline film [26], if the film resides in the emeraldine state. This galvanic interaction will drive the polymer to the lower oxidation states avoiding the formation of the pernigraniline oxidation state, which is normally associated with polymer degradation. Indeed, when the polyaniline-coated iron system is immersed under open-circuit conditions in an oxygenated solution, it maintains the green coloration characteristic of the lower oxidation states, whereas the polymer formed at platinum undergoes oxidation. However, this galvanic interaction will ultimately lead to the generation of dissolved iron within the polymer film.
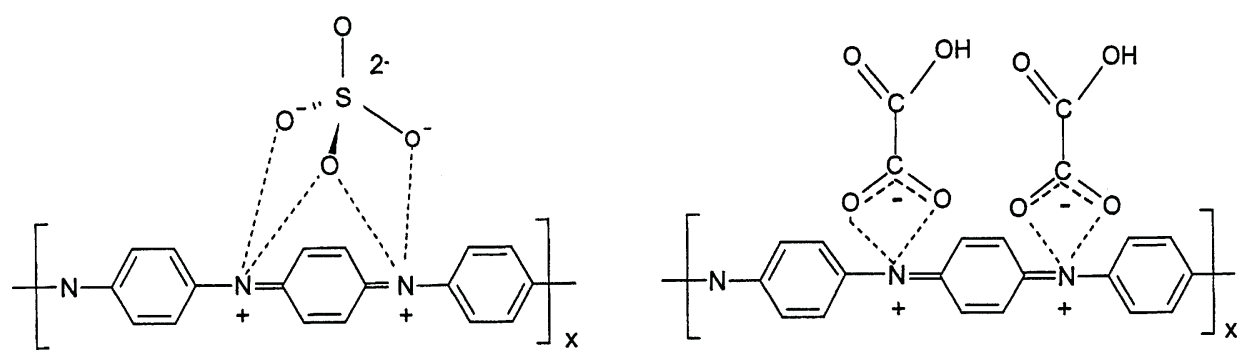

Fig. 7. Schematic representation of the shielding effect of sulphate and oxalate anions from nucleophilic attack of the bipolaron sites of polyaniline. 


\section{Conclusions}

Polyaniline films, grown from $0.1 \mathrm{~mol} \mathrm{dm}^{-3}$ oxalic acid at an iron electrode, are less susceptible to degradation under high anodic potentials than films grown at platinum electrodes from sulphuric acid. This appears to be connected to the presence of oxalate anions in solution, which offer a greater shielding of polyaniline bipolarons than the sulphate counter ions. The soluble degradation product, benzoquinone, was detected on the cycling of polyaniline formed at platinum using high potentials. However, this product was not detected during the electrosynthesis of polyaniline at iron using higher potential limits.

\section{Acknowledgements}

The authors gratefully acknowledge the support of this work by Enterprise Ireland, under the Research Innovation Fund.

\section{References}

[1] A. Mirmohseni, R. Solhjo, Eur. Polym. J. 39 (2003) 219.

[2] J.L. Wang, J. Yang, J.Y. Xie, N.X. Xu, Adv. Mater. 14 (2002) 963.

[3] J.L. Boehme, D.S.K. Mudigonda, J.P. Ferraris, Chem. Mater. 13 (2001) 4469.

[4] D. Sazou, C. Georgolios, J. Electroanal. Chem. 429 (1997) 81.
[5] J.L. Camalet, J.C. Lacroix, S. Aeiyach, K. Chane-Ching, P.C. Lacaze, Synth. Met. 93 (1998) 133.

[6] M. Kraljić, Z. Mandić, Lj. Duić, Corros. Sci. 45 (2003) 181.

[7] M.C. Bernard, A. Hugot-LeGoff, S. Joiret, P.V. Phong, Synth. Met. 119 (2001) 283.

[8] N.M. Martyak, P. Mc Andrew, J.E. Mc Caskie, D. Dijon, Prog. Org. Coat. 45 (2002) 23.

[9] R. Rajagopolan, J.O. Iroh, Electrochim. Acta 46 (2003) 2443.

[10] J.L. Camalet, J.C. Lacroix, S. Aeiyach, K. Chane-Ching, P.C. Lacaze, J. Electroanal. Chem. 416 (1996) 179.

[11] M.A. Malik, M.T. Galkowski, H. Bala, B. Grzybowska, P.J. Kulesza, Electrochim. Acta 44 (1999) 2157.

[12] T. Kobayashi, H. Yoneyama, H. Tamura, J. Electroanal. Chem. 177 (1984) 293.

[13] D. Stilwell, S.-M. Park, J. Electrochem. Soc. 135 (1988) 2497.

[14] C.Q. Cui, L.H. Ong, T.C. Tan, J.Y. Lee, Electrochim. Acta 38 (1993) 1395.

[15] L. Duić, Z. Mandić, S. Kovać, Electrochim. Acta 40 (1995) 1681.

[16] H.N. Dinh, J. Ding, S.J. Xia, V. Birss, J. Electroanal. Chem. 459 (1998) 45.

[17] D.E. Stilwell, S.-M. Park, J. Electrochem. Soc. 135 (1988) 2254.

[18] G. Mengoli, M.M. Musiani, Electrochim. Acta 31 (1986) 201.

[19] W. Zheng, M. Angelopoulos, A.J. Epstein, A.G. MacDiarmid, Macromolecules 30 (1997) 2953.

[20] W. Zheng, M. Angelopoulous, A.J. Epstein, A.G. MacDiarmid, Macromolecules 30 (1997) 7634.

[21] J. Lippe, R. Holze, J. Electroanal. Chem. 339 (1992) 411.

[22] M. Lapkowski, E.M. Genies, J. Electroanal. Chem. 279 (1990) 157.

[23] K.D. Dobson, A.J. McQuillan, Spectrochim. Acta A 55 (1999) 1395.

[24] L.A.G. Rodenas, A.M. Iglesias, A.D. Weisz, P.J. Morando, M.A. Blesa, Inorg. Chem. 36 (1997) 6423.

[25] C. Zhu, C. Wang, L. Yang, C. Bai, F. Wang, Appl. Phys. A: Mater. 68 (1999) 435.

[26] W.K. Lu, R.L. Elsenbaumer, B. Wessling, Synth. Met. 71 (1995) 2163. 